Página inicial: 211 - Página Final: 224

Tipo de artículo: Investigación.

\title{
La significación del poder político y la acción en la justicia transicional colombiana: Hacia la búsqueda de la paz en Colombia.i
}

\author{
The Significance of the Political Power and the Action in the Colombian \\ Transitional Justice: The Search for Peace in Colombia.
}

\author{
Por: Leonardo Sabogal Murcia ${ }^{1}$
}

Recibido: junio de 2016 Revisado: noviembre de 2016 Aceptado: diciembre de 2016

\section{Resumen.}

De acuerdo a la concepción del poder y de la acción político-estratégica que se conciba dentro de la ciudadanía y la institucionalidad, tendremos un menor o mayor acercamiento a las transformaciones necesarias para la finalización del conflicto armado no internacional colombiano. Es así que, es importante pensar la justicia transicional, el poder y la paz como una ecuación que debería llevar a un renacer de la Nación colombiana.

Palabras claves. Poder político, conflicto armado, justicia transicional, paz en Colombia.

\begin{abstract}
.
According to the conception of power and the political-strategic action, which is conceived within citizenship and Institutionality, there will have a minor or major approach to the transformations necessary for the ending of the non-international Colombian armed conflict. Then, it is necessary to think about the transitional justice, power, and peace as an equation, which would make the Colombian nation be born again.
\end{abstract}

Key words. Political Power, Armed Conflict, Transitional Justice, and Peace in Colombia.

1 Docente Investigador, Universidad de San Buenaventura Cali (Colombia). Contacto: leonardo.sabogal@gmail.com ; 1sabogal2@usbcali.edu.co 


\section{Introducción.}

Existe una preocupación latente por las cifras desbordadas de violencia organizada y sistemática, que traslucen la concepción de poder predominante en las instituciones y en la ciudadanía colombiana, pero que de una forma crítica deben replantearse desde una acción estratégica para la vida y alcanzar un poder político alternativo, creativo y vital mucho más apropiado para la paz de Colombia.

Esta realidad exige, entre otras, una apuesta por hacer un análisis de un fenómeno jurídico como la justicia transicional desde un marco teórico histórico y filosófico, apoyado en varios autores y en la evidencia recogida por centros de estudio oficiales que trabajan en pro de la consecución de la paz.

En últimas, el horizonte del artículo, necesita de otros momentos analíticos para hacer entrega de otros avances complementarios, que incluyan más categorías filosóficas -como la banalidad del mal, el pueblo, la alteridad, el consenso, entre otras- y de otros pensadores propicios para la búsqueda de la paz. En todo caso, es un texto que tan sólo inicia un debate en torno al poder y a la acción estratégica como categorías de análisis para la posibilidad de una paz socio-política en Colombia.

\section{Metodología.}

Se ha utilizado el método hermenéutico cualitativo, teniendo como fuentes de caracterización, una filtrada documentación estadística, artículos científicos dentro de la línea de investigación, libros de base teórica, informes de estudio oficiales y otros trabajos bibliográficos en la red. Entonces, la interpretación de los textos incluidos como estado del arte, está enfocada en el poder político y la acción como categorías al encuentro de la justicia transicional, teniendo como marco teórico la filosofía política de Arendt y E. Dussel. Logrando demostrar una hipótesis fundamental del artículo, de acuerdo a la concepción del poder y de la acción político-estratégica que se conciba dentro de la ciudadanía y la institucionalidad, tendremos un menor o mayor acercamiento a las transformaciones necesarias para la finalización del conflicto armado no internacional colombiano.

\section{Resultados.}

\section{El contexto del conflicto y la entrada transicional hacia la paz.}

El contexto colombiano actual nos lleva a confrontar dos posibilidades -la paz y la guerra-, que hoy en día parecen meros momentos de cotidianidad nacional, pero en ellos se encierra una racionalidad definitoria: la vida y la muerte. Esas dos categorías, que van más allá de la metafísica para trascender por la política, por la comunidad de vida. La pretensión no es otra que aportar a la discusión acerca de la paz y el conflicto en Colombia desde el pensamiento arendtiano, tomando como marco de apoyo, la acción y el poder, sin dejar de lado otros elementos de interés como la justicia transicional actual y desentrañar un poco la importancia del perdón en esta etapa contemporánea de Colombia.

El poder político y la acción como categorías relacionadas con la justicia transicional y el perdón dentro del conflicto colombiano, a partir del pensamiento de Hannah Arendt. 
Sin duda alguna, hacer un intento por buscar la paz, se encuentra más que justificado en un país con más de cinco décadas de confrontaciones violentas; un conflicto catastrófico y de grandes magnitudes no solo para Colombia, sino para la humanidad. Para hacer una idea mínima de esto.

Basta con decir que entre 1958 y el 2012 murieron 220.000 personas como consecuencia del conflicto armado. Esto equivale a toda la población de una ciudad como Sincelejo o Popayán. Esta cifra también permite confirmar que una de cada tres muertes violentas del país la produce la guerra, y que, durante cinco décadas, en promedio, todos los días murieron 11 personas por esta causa. Lo más grave es que 180.000 de esos muertos (el 81\%) eran civiles. La guerra colombiana no ha sido una guerra de combatientes, sino que todos han enfilado sus fusiles contra quienes están desarmados. A veces de manera colectiva, con masacres, pero la mayor parte del tiempo de manera selectiva a través de sicarios o comandos que actúan rápido y casi siempre sin dejar huella. [...]Aunque en casi todas las guerras contemporáneas los civiles son quienes sufren más, en Colombia hay dos rasgos particulares: que la mayor parte de estas muertes ocurrieron de manera cotidiana, selectiva, silenciosa, en partes muy alejadas de los centros urbanos, y por tanto, han pasado inadvertidas para la mayoría de la sociedad. Y segundo, que estuvieron acompañadas de crueldad y terror. El otro gran crimen que ha gozado de invisibilidad y ocultamiento es la desaparición forzada. El Registro Único de Víctimas de la Unidad para Atención y Reparación Integral a las Víctimas reporta 25.007 casos ocurridos desde 1985 hasta el 2012. No obstante, los casos de desaparición forzada se remontan a la década del setenta, lo que puede elevar el registro a 27.000 desaparecidos si se tienen en cuenta los casos documentados por las organizaciones de derechos humanos y familiares de víctimas." (Centro Nacional de Memoria Histórica, 2014)

$\mathrm{Y}$ es precisamente la indolencia, la insensibilidad e incluso la indiferencia, algunas de las peores consecuencias de este conflicto, desde el punto de vista crítico-racional para la sociedad colombiana. Se ha convertido en algo superfluo y "normal", que la ciudadanía en medio de los pasillos y de las calles, comente y relate sin asombro alguno, acerca de homicidios selectivos, de desapariciones forzadas, de torturas, de desplazamiento forzado, de violaciones y masacres, sin ningún ápice de indignación o preocupación moral; se vive una detención de la criticidad y se perfila con el tiempo una respuesta unánime de conformismo y cuando no, un sentimiento de venganza respecto a los grupos armados subversivos.

El compromiso con una sociedad sumida en una crisis moral -amoral tal vez- no se puede reducir a terminar o no un conflicto armado mediante la guerra o la negociación, también debe preguntarse por sus causas, por sus efectos, por los fundamentos para la búsqueda de una paz ciudadana e institucional, por los elementos para una solución racional que garantice la no repetición del dolor y del horror propios de una guerra -al menos, con una intensidad incomparable frente a los tiempos de oscuridad que hemos vivido-.

Desde los años setenta el secuestro se convirtió en una modalidad de violencia usada por las guerrillas (en un 90\%) con fines económicos o políticos, y prácticamente no hay grupo insurgente que no haya recurrido a él. Para entender la magnitud de lo que ha sido el secuestro en el conflicto basta con constatar que el Grupo de Memoria Histórica pudo documentar 27.023 casos, 16.000 de los cuales se registraron entre 1996 y el 2002. El otro delito no letal que ha cambiado por completo al país es el desplazamiento forzado. La cifra oficial asciende a 4.744 .046 personas y se estima que por lo menos 8,3 millones de hectáreas y 350.000 predios fueron abandonados o despojados. Durante los peores años del conflicto, entre 1996 y el 2002, fueron desplazadas 300.000 personas por año. Si se concentrara a los desplazados en un nuevo asentamiento urbano, este constituiría la segunda ciudad más grande de Colombia después de Bogotá. (...) El desplazamiento forzado ha sido también un 
crimen invisible, ya que el $73 \%$ de las personas tuvieron que desplazarse de manera individual y no en los éxodos que han sido registrados por la prensa. (Centro Nacional de Memoria Histórica, 2014)

El gobierno actual está en un proceso de negociación con el grupo guerrillero más fuerte en el país, las Fuerzas Armadas Revolucionarias de Colombia. Ejército del Pueblo (FARC-EP). Estos diálogos de la Habana han sido muy cuestionados, desde diferentes aristas, como, por ejemplo: la relación entre castigo e impunidad, las formas alternativas de pena, la negociación en medio de fuego cruzado, entre otros. Antes se debe anotar, que el conflicto colombiano está integrado por diferentes actores bélicos, entre ellos: paramilitarismo, guerrillas, bandas criminales (paramilitares desmovilizados pasajeramente) y el Estado. Lamentablemente, el Estado colombiano ha sido responsable de diferentes violaciones a los derechos humanos y al derecho internacional humanitario.

Por tanto, la población civil ha sido victimizada constantemente por estos actores, unos más victimarios que otros, pero al fin y al cabo perpetradores de la violencia organizada. Con esto, a manera de marco contextual del problema investigativo, se puede observar la necesidad de encontrar vías razonadas para la paz y la convivencia ciudadana. Además, en Colombia se han dado varias oportunidades para la paz negociada, una de las más recordadas dentro del modelo de justicia transicional se dio a finales de los ochenta y comienzos de los noventa con el Movimiento Guerrillero 19 de abril (M-19), integrantes desmovilizados, quienes más adelante fueron la base para la conformación de un partido político denominado Unión Patriótica (UP). La mayoría de los líderes de dicho partido, fueron asesinados selectivamente y durante un período no mayor a diez años, las cifras no oficiales hablan de un número aproximado a los 5.000 militantes ejecutados y/o desaparecidos de manera forzosa.

Todo lo anterior da cuenta de varios aspectos: a) por un lado, la magnitud catastrófica del conflicto colombiano; b) su dinámica de desconfianza y venganza dentro de los procesos de negociación transicional; c) la intensificada e indiscriminada violación a los derechos humanos y al derecho internacional humanitario; d) la incredulidad socio-política y jurídica de los ciudadanos hacia la terminación del conflicto en forma pacífica; e) la falta de participación civil en los procesos de paz como factor de determinación para su eventual falla; y f) la necesidad de enriquecer y aportar desde la comunidad a un proceso real y efectivo de paz -bajo un paradigma interdisciplinar- en el caso propio, intentando comprender algunas elaboraciones filosóficas y jurídicas.

La situación es muy compleja en términos de sistema como lo plantea Rolando García (2006), pero desde el poder político y la acción, se pueden ofrecer elementos mínimos para el perdón como contribución en la búsqueda de la paz. Para esto es necesario, entablar tres puntos: el poder político, la acción y el perdón -aclarando lo incipiente que puede resultar este trabajo. No obstante, antes de entrar a la temática de poder político, es necesario plantear la importancia y la dinámica dogmática de la justicia transicional, pues es en este tipo de justicia, donde se van a evidenciar las categorías de poder político, acción y perdón -siendo este último, un concepto difícilmente sustentado en esta investigación, como poco se ha sustentado o poco interés ha generado en la ciencia jurídica y en la ciencia política. 


\section{Justicia transicional en Colombia: mirando hacia la paz y respondiendo coyunturalmente.}

La justicia transicional durante mucho tiempo se entendió como un modelo de justicia necesario para la transición de regímenes autoritarios hacia sistemas democráticos, así como para la superación de guerras internacionales en la búsqueda de la paz. Sin embargo, hoy en día los alcances de este modelo han variado para fortuna de diferentes países, que, como Colombia, sufren y han vivido los denominados conflictos internos. Se ha definido la justicia transicional por parte del Consejo de Seguridad de Naciones Unidas como un modelo que:

Abarca toda la variedad de procesos y mecanismos asociados con los intentos de una sociedad por resolver los problemas derivados de un pasado de abusos a gran escala, a fin de que los responsables rindan cuentas de sus actos, servir a la justicia y lograr la reconciliacio $\square$ n. Tales mecanismos pueden ser judiciales o extrajudiciales y tener distintos niveles de participacio $\square \mathrm{n}$ internacional (o carecer por completo de ella) asi $\square$ como abarcar el enjuiciamiento de personas, el resarcimiento, la bu $\square$ squeda de la verdad, la reforma institucional, la investigacio $\square \mathrm{n}$ de antecedentes, la remocio $\square \mathrm{n}$ del cargo o combinaciones de todos ellos". (Consejo de Seguridad de las Naciones Unidas S/2004/616, 2004)

Por su parte el Centro Internacional para la Justicia Transicional (2009) indica que, "la justicia transicional no es una forma especial de justicia, sino una justicia adaptada a sociedades que se transforman a si $\square$ mismas despue $\square$ s de un peri $\square$ odo de violacio $\square$ n generalizada de los derechos humanos." (ICTJ, 2015). Esto es precisamente una caracterización de lo que sucede en Colombia respecto a dicha materia, y por eso la discusión oficial para algunas de esas potenciales transformaciones se están dialogando en La Habana - Cuba entre la guerrilla de las Fuerzas Armadas Revolucionarias de Colombia-Ejército del Pueblo (FARC-EP) y el Gobierno Nacional, sin que haya una certeza en términos de tiempo para los acuerdos definitivos y posteriormente para su implementación democrática e institucional.

La justicia transicional es uno de los grandes desafíos dentro de sociedades que aspiran a llegar a una estabilidad democrática o desean liberarse de la violencia de confrontación militar organizada, pues está herramienta debe actuar bajo el marco de los derechos humanos, el derecho internacional humanitario, evitando en ambas situaciones la impunidad, la falta de verdad o la desvaloración moral y material de las víctimas.

Así las cosas, David Crocker en su análisis de los procesos de justicia transicional establece que estos pueden tomar como derroteros: a) la reconstruccio $\square$ n de la verdad; b) la implementacio $\square \mathrm{n}$ de reformas institucionales tendientes a la recuperacio $\square \mathrm{n}$ de la confianza en el Estado alli $\square$ donde este ha sido un actor en las violaciones a los derechos humanos e infracciones al dih; c) la garanti $\square$ a de escenarios pu $\square$ blicos para la deliberacio $\square$ n en torno al conflicto; d) la materializacio $\square$ n de la reparacio $\square$ n integral a las vi $\square$ ctimas; e) la garanti $\square$ a de una plataforma pu $\square$ blica de participacio $\square \mathrm{n}$ de estos sectores; f) la determinacio $\square \mathrm{n}$ de responsabilidades penales; y, g) la reconciliacio $\square$ n y el perdo $\square$ n. (Crocker, 2011)

La justicia transicional puede tener estos derroteros de los que habla Crocker, pero no existe una fórmula única para determinar el éxito de un modelo transicional, sobre todo, por su temprana aparición paradigmática e institucional. Dice Uprimny \& Guzmán-Rodríguez, que:

El paradigma de la justicia transicional es relativamente reciente, pero ha tenido un amplio desarrollo desde los años ochenta del siglo pasado y su importancia sigue en aumento. La mejor prueba de ello es el proceso de institucionalizacio $\square \mathrm{n}$ que se ha verificado, mediante la creacio $\square \mathrm{n}$ de tribunales 
internacionales e hi $\square$ bridos, las comisiones de la verdad y los programas de reparacio $\square$ n. La justicia transicional sigue siendo, sin embargo, un paradigma en desarrollo que adquiere formas específicas de acuerdo con las condiciones y el contexto en el cual es aplicado. La experiencia comparada muestra que este concepto se concreta en diferentes disen $\square$ os institucionales que dan lugar a diversos tipos de transicio $\square$ n”. (2010)

\section{Un recuento jurídico sobre la justicia transicional en Colombia.}

La legislación colombiana ha determinado construir un modelo de justicia transicional, a pesar de la perduración del conflicto bélico no internacional, contrario al modelo tradicional, el cual genera disposiciones y estructuras transicionales en la etapa de posconflicto. Este ejercicio en Colombia asume sus riesgos, pero puede ser conveniente si las partes hacen un desescalamiento de la guerra de manera racional y efectiva. Para ello, se han elaborado una serie de mecanismos jurídicos tanto legislativos como judiciales, tratando de brindar una suerte de legitimidad institucional a los acuerdos y a los procesos suscitados entre las partes del conflicto en Colombia.

En Colombia se habla concretamente de justicia transicional a partir de la ley 975 de 2005, conocida como "Ley de Justicia y Paz", sin descartar que en la ley 418 de 1997, ya empezaban a formularse algunas estrategias relacionadas con justicia transicional. La ley 975 pretendía facilitar procesos de paz con los diferentes actores armados ilegales, buscando la desmovilización y la reincorporación a la vida civil de quienes militaban dentro de dichas organizaciones. A este proceso legal, sólo acudieron los paramilitares, y está ley fue tan criticada, entre otras razones, porque más que una estrategia modular para la justicia transicional, simplemente se estableció como un marco legal de mera desmovilización armada. Está ley 975 de 2005 fue demandada en varias oportunidades, y a su paso por la Corte Constitucional, arrojó en su análisis un fallo especializado en materia de justicia transicional, la sentencia C-370 de 2006, donde se hace una revisión histórica y conceptual del modelo y se reconoce la importancia de la justicia transicional para Colombia y las tensiones entre la justicia (posible impunidad) y los derechos de las víctimas.

Luego, aparece la sentencia C-936 de 2010 donde se determinó la inexequibilidad del principio de oportunidad contemplado en el numeral 17 parágrafo $3^{\circ}$ del arti $\square$ culo $2^{\circ}$ de la Ley 1312 de 2009, norma destinada a la desmovilización de más de veinte mil personas no incluidas en el proceso de justicia y paz. En ese momento se promueve otro proyecto de ley por parte del Gobierno Uribe Vélez, que termina decantado en la ley 1424 de 2010 -ley que desde su encabezado habla y dispone expresamente sobre medidas de justicia transicional-. Está ley fue demandada y de ella se rescata la sentencia C-771 de 2011, donde de nuevo se perfila el concepto de justicia transicional, sus alcances en el derecho comparado, y se le da el visto bueno como una estrategia adecuada para el contexto colombiano.

Por último, aparece la ley 1448 de 2011 como una ley que incluye de mejor manera a las víctimas dentro de la concepción de justicia transicional -el enfoque estaba muy centrado en los actores armados del conflicto- que hasta ese momento se había elaborado jurídicamente por parte de las instituciones de Colombia. La ley 1448 de 2011 es tal vez la ley más completa en materia de justicia transicional, pues es la ley más ajustada a los estándares internacionales y define en su artículo $8^{\circ}$ la justicia transicional, "entiéndase por justicia transicional los diferentes procesos y mecanismos judiciales o extrajudiciales asociados con los intentos de la sociedad por garantizar que los responsables de las violaciones contempladas en el artículo 3o de la presente ley rindan cuentas de sus actos, se satisfagan los derechos a la justicia, la verdad y la reparación integral a las víctimas, se lleven a cabo las reformas institucionales necesarias para la no repetición 
de los hechos y la desarticulación de las estructuras armadas ilegales, con el fin último de lograr la reconciliación nacional y la paz duradera y sostenible" y dice la remisión normativa del artículo $3^{\circ}$ lo siguiente:

Víctimas. Se consideran víctimas, para los efectos de esta ley, aquellas personas que individual o colectivamente hayan sufrido un daño por hechos ocurridos a partir del $1^{\circ}$ de enero de 1985 , como consecuencia de infracciones al Derecho Internacional Humanitario o de violaciones graves y manifiestas a las normas internacionales de Derechos Humanos, ocurridas con ocasión del conflicto armado interno $(\ldots)$

El concepto de víctima ha sido una mera legalidad administrativa, indicando inclusive una fecha de inicio para el reconocimiento de víctima, que guarda su justificación en la conocida "Toma del Palacio de Justicia" por parte del grupo guerrillero Movimiento 19 de abril (M-19) el 6 de noviembre de 1985. Aunque la determinación de esta fecha se discutió en el Congreso de la República, se decidieron por este evento y no por el magnicidio de Jorge Eliecer Gaitán, quien fuera el líder político y social más reconocido del siglo XX en Colombia, candidato presidencial -y seguro ganador de esas elecciones- asesinado el 9 de abril de 1948; muerte que generó el denominado "Bogotazo" -el hecho de sublevación nacional más complejo de la historia, liderado por las masas populares e inclusive algunas facciones policiales durante casi cuatro días, en el cual murieron miles de civiles-. Lo relevante de dicho acontecimiento, es que básicamente se convierte en el factor de creación de las guerrillas populares y campesinas de la década de los años cincuenta y con ello, en el comienzo del conflicto armado colombiano.

Lo cierto es que la toma del palacio era más "conveniente" para la dirigencia nacional en términos administrativos, financieros y logísticos en comparación con la muerte de Jorge Eliecer Gaitán y el bogotazo. Fue algo que no tuvo más deliberación que la del propio Congreso y en lo cual, la participación ciudadana fue prácticamente nula. Esa es parte de la justicia transicional adeudada dentro del proceso legislativo tendiente al posconflicto. En todo caso, la ley 1448 ha brindado más elementos para la optimización de la justicia transicional en Colombia, a pesar de ser una ley anterior al acto legislativo 01 de 2012, denominado "Marco Jurídico para la Paz", el cual debió haber sido el primer paso de la justicia transicional en materia jurídica -constitucionalen Colombia. Algo poco entendible en términos constitucionalistas, pero apenas lógico para un país que busca soluciones coyunturales a problemas estructurales. Con toda razón Orjuela \& Lozano señalan que:

En un pai $\square$ s que lleva casi cincuenta an $\square$ os en guerra, eludir la regulacio $\square$ n constitucional sobre derechos de las vi $\square$ ctimas, con base en restricciones empi $\square$ ricas insuficientemente demostradas es poli $\square$ ticamente sensible y normativamente problema $\square$ tico. No basta con afirmar que "este es un contexto de JT". La regulacio $\square \mathrm{n}$ en mencio $\square \mathrm{n}$ sigue siendo va $\square$ lida y su inobservancia normalmente genera consecuencias disciplinarias y penales para los funcionarios que proceden de esa manera. La reglamentacio $\square$ n colombiana sobre derechos de las vi $\square$ ctimas es una conquista democra $\square$ tica de un movimiento de derechos humanos vigoroso pero perseguido". (2012)

Este acto legislativo fue demandado, a raíz de ello, apareció el pronunciamiento de la Corte Constitucional bajo la sentencia C-579 de 2013, en dicha sentencia se desarrollan varias temáticas, entre ellas: la justicia transicional como instrumento excepcional; los derechos de las víctimas a la verdad, la justicia, la reparación integral y la garantía de no repetición; la implementación de mecanismos extrajudiciales en materia de verdad y reparación para las víctimas; la prohibición expresa de connotar como delito político a los delitos de lesa humanidad y genocidio; la creación de una comisión de la verdad; la restitución de tierras a las víctimas 
(desplazamiento forzado interno) -algo muy importante, teniendo en cuenta que la tierra es un gran motor del conflicto colombiano-; entre otras.

En este desarrollo legislativo y jurisprudencial de la justicia transicional, la ciudadanía no ha jugado un papel participativo, pues la concepción del poder político tradicional y de corte dominante, no permite un ejercicio del poder creativo e inclusivo. La paz es una preocupación nacional, no es tan solo un problema de legal, la legalidad es una herramienta, pero no es una solución. Las víctimas debieron ser vistas y oídas, debieron expresar su querer (querer vivir querer poner) a las instituciones, a las comunidades y a los diversos sectores que la integran. Para tener una idea de esto, se observó páginas arriba como la justicia transicional en Colombia, llegó a valorar el papel de las víctimas de manera tardía. Esto es una consecuencia esperada dentro de una institucionalidad construida bajo la imposición y no bajo la horizontalidad de su ciudadanía.

\section{El poder político como elemento para la paz.}

El poder político está relacionado con la justicia transicional, como también lo está con el concepto de perdón -este último, para un posterior desarrollo investigativo-. La justicia transicional es un proceso político antes que jurídico, no habrá leyes ni jurisprudencia sobre justicia transicional exitosas en Colombia, si no hay compromiso y voluntad de hacer la paz por parte del gobierno, las FARC y la sociedad civil. Buscar el posconflicto y la construcción de paz implica una alta politización del Derecho, por ello:

Lo que era históricamente visto como un fenómeno legal asociado a condiciones post-conflicto extraordinarias, ahora parece ser cada vez más un reflejo de tiempos normales. La guerra en tiempos de paz, la fragmentación política, Estados débiles, guerras pequeñas y el conflicto permanente, todas son características condiciones políticas contemporáneas. Estos acontecimientos contemporáneos han estimulado el intento de lograr una normalización de la justicia transicional, conduciendo en última instancia a consecuencias ambivalentes. En su condición de una teoría asociada al cambio político permanente, la justicia transicional se relaciona con una politización más alta del derecho y también con un cierto grado de concesiones en los estándares del estado de derecho. (Teitel, R, 2003)

El hemisferio occidental -con mayor énfasis en la modernidad- ha tenido y ha desplegado un poder político de carácter dominante, vertical, inclusive reduccionista, un poder político weberiano como dominación (un sentido negativo de poder). Lo expresa así: "Poder significa probabilidad de imponer la propia voluntad dentro de una relación social, aun contra toda resistencia y cualquiera que sea el fundamento de esa probabilidad. Por dominación debe entenderse la probabilidad de encontrar obediencia a un mandato de determinado contenido entre personas". (Weber, M, 1944) Esa imposición ha hecho de los sistemas políticos y de los gobiernos modernos, una estructura de dominación y negación constante del Otro. El mandato que "entregan" los ciudadanos representados a los ciudadanos representantes, ha sido históricamente, un mandato electoral, más no político - de ahí que se entienda agotada la democracia, con el simple sufragio-, de ser un mandato político obediencial (delegar el poder político, pero jamás entregarlo), tendríamos en efecto, un poder político responsable, de ciudadanos reales, plurales, con discurso y promesa. Es por eso que:

Cuando en el EZLN, los Zapatistas expresan que no es lo mismo que: a) «los que mandan, mandan mandando» (que en nuestra terminología será expresión de la protesta negativa o el poder institucionalizado que, siendo delegación del ejercicio que viene de la comunidad política, se fetichiza independizándose y pretendiendo soberanía por sí misma), a que b) «los que mandan mandan obedeciendo» (que significa que la potestas se funda en la potentia), nos dan claras indicaciones para 
saber pensar la esencia del poder político, contra el modelo moderno del poder como dominación. Es además interesante que Weber incluye a su descripción de poder como dominación el hecho de «encontrar obediencia a un mandato de determinado contenido entre personas» — cita anterior- El «mandato» encuentra «obedientes», es decir, «manda mandando». En cambio, el que «manda obedeciendo» parte de un grupo de personas que le han dado el contenido como mandato al que manda. (Dussel, E, 2009)

Con toda razón, desde una concepción del poder político negativa, poco podrá darse en términos justos y equitativos, una negociación o un proceso de distención conflictual. Dado que, niego al otro -sea mi amigo, con mayor mi enemigo retomando a C. Schmitt- o no lo dejo aparecer, porque no quiero escuchar su discurso y desconozco sus acciones por cualquier motivo, en últimas, no lo reconozco. El alcance es tal, teniendo en cuenta, que los gobiernos de Colombia en muchas ocasiones desconocen sus contradictores u opositores políticos institucionales, que podría entonces esperarse ante sus contradictores armados, llevarlos al aniquilamiento - retomando de nuevo la dinámica violenta de C. Schmitt- la promoción de la guerra y la venganza.

En este punto, bien indica Arendt, la importancia de la aparición como una característica de un verdadero poder, que, aunque ella no lo diga, es un poder de vida, de nacer y crecer, diferente al poder convencional de morir y someterse. No es el reduccionismo voluntarista y estratégico de Schmitt lo que debe seguir imperando, si lo que desea la institucionalidad, la sociedad y los guerrilleros es la paz. Lo que debe empezar a transformarse dentro de un Estado violento, es su concepción estructural de poder, determinando un nuevo y cercano camino a los estándares de justicia internacional y al perdón como una categoría más allá de esa justicia administrada.

Arendt manifiesta con acierto, que: "El espacio de aparición cobra existencia siempre que los hombres se agrupan por el discurso y la acción, y por lo tanto precede a toda formal constitución de la esfera pública y de las varias formas de gobierno (...)" (2005). Se requiere que el ciudadano aparezca, que la pluralidad y la diferencia aparezcan, que el guerrillero aparezca, que la sociedad civil aparezca, porque hasta hoy, todo es un mono-discurso y una acción unilateralsin desatender que hoy se tiende un pequeño puente para negociar pacíficamente el conflicto armado y con ello, transformar el poder político y su constitución-. Tal vez, el gobierno actual y otros sectores nacionales, están empezando a hacer un viraje, entendiendo que, si no hay otra forma de entender la política, esta acción procesual fracasará como las anteriores. Por eso, afirma Arendt que

lo que primero socava y luego mata a las comunidades políticas es la pérdida de poder y la impotencia final; y el poder no puede almacenarse y mantenerse en reserva para hacer frente a las emergencias, como los instrumentos de la violencia, sino que sólo existe en su realidad”. (2005)

El poder se ha diezmado tanto en Colombia, y es precisamente eso, lo que ha generado una excesiva presencia de muerte e impotencia; cuando el sistema institucional se ha visto amenazado por una violencia ilegal, el Estado ha querido hacerle frente a esa amenaza -guerrillera en este caso- con instrumentos de violencia militar, judicial y comunicativa, logrando con ello, una mayor reacción de su enemigo, hasta el punto de trasladar el conflicto a los espacios de la población civil y violar el derecho internacional humanitario.

El proceso hacía la paz es una oportunidad para renacer, para crear nuevas realidades y trasformar efectivamente las causas que dieron lugar al dolor. Y para eso, como dice Arendt, hay que entender que el poder: "sólo es realidad donde palabra y acto no se han separado, donde las 
palabras no están vacías y los hechos no son brutales, donde las palabras no se emplean para velar intenciones sino para descubrir realidades, y los actos no se usan para violar y destruir sino para establecer relaciones y crear nuevas realidades. (2005)

Cuando se habla de la verdad dentro de un conflicto, se deben descubrir realidades, las de las víctimas, las de los victimarios, las que la sociedad anhela conocer para no repetir, para no olvidar. Además, actos que no destruyan -cosa que sigue haciendo la guerrilla y el propio Estadopues dos pasos que se avancen, no pueden terminan siendo tres pasos hacia atrás eventualmente. Tanto las FARC-EP como los gobiernos colombianos, desde hace más de cincuenta años, han confiado en la fuerza como sinónimo equívoco de poder. Y se han dispersado y han dispersado a la comunidad, de tal forma, que los ciudadanos reproduciendo el modelo de poder impotente de estos dos actores, han encontrado en las acciones estratégicamente violentas, su mejor performance de fuerza individualista. La separación de los hombres ha victimizado política y organizacionalmente a la ciudadanía, un país polarizado y una institucionalidad fallida, presa del narcotráfico y la corrupción. Esto ha dado lugar a una crisis de partidos políticos, que han dejado de ser partidos para convertirse en caudillismos y facciones de motivación electoral mercantilizada. Debe entenderse, que, para la consecución de la paz y la superación del conflicto colombiano, la generación de poder debe provenir del vivir unido del pueblo. "Sólo donde los hombres viven tan unidos que las potencialidades de la acción están siempre presentes, el poder puede permanecer con ellos, y la fundación de ciudades, que como ciudades-estado sigue siendo modelo para toda organización política occidental, es por lo tanto el más importante prerrequisito material del poder". (Arendt, 2005) De esta manera, se da paso a la importancia de analizar la acción, pues en ella, se debe buscar como finalidad estratégica dentro de la esfera público-política, la paz y la democracia para la terminación de la guerra.

\section{La acción (político-estratégica): acción para la paz.}

La acción es un nivel de la política determinante, es un proceso dentro del poder político trascendental. Aunque dentro de sus características se encuentre la incertidumbre, la contingencia y la imprevisibilidad, la acción es funcional y estratégica para el desenvolvimiento de los sujetos y de las instituciones. Lo que requiere la acción es básicamente, pluralidad humana y discurso, pues, la acción se hace para convencer e impactar en los demás y para hacerlo se necesita de forma indispensable, el discurso, el reconocimiento. En el caso de la pluralidad humana dice Arendt, que es:

Básica condición tanto de la acción como del discurso, tiene el doble carácter de igualdad y distinción. Si los hombres no fueran iguales, no podrían entenderse ni planear y prever para el futuro las necesidades de los que llegarán después. Si los hombres no fueran distintos, es decir, cada ser humano diferenciado de cualquier otro que exista, haya existido o existirá, no necesitarían el discurso ni la acción para entenderse. Signos y sonidos bastarían para comunicar las necesidades inmediatas e idénticas. (2005)

La significación de la pluralidad humana está puesta en la mesa del conflicto colombiano. Existen unos diálogos (acciones) para tratar de acordar la paz. En efecto, hay dos partes, que deben saber que son iguales en cuanto negociadores, pero son distintos en cuanto cada uno representa un imaginario y unos intereses diferentes. Los sub-acuerdos que se han ido construyendo, terminan siendo una especie de planeación para el futuro -pensando en las generaciones venideras- una planeación aún incierta conforme a la continuidad del proceso y la definición presidencial del país. Pero aun así y con sus pormenores, gobierno y FARC, al parecer 
han estado generando acción desde ambos lados, guiados por la finalidad última de pactar una paz definitiva.

La idea inicial de la guerrilla en Colombia, supone un ánimo altruista y sus acciones tienen una pretensión reformista del Estado constitucional imperante. La respuesta del Estado es una reacción apenas lógica de defensa y luego de ataque. No obstante, las motivaciones de uno y otro en la medida que transcurre el tiempo se han ido diluyendo; por el lado de las guerrillas su actuar ha venido siendo probadamente vinculado al narcotráfico - por dar un ejemplo- y por el lado del gobierno, su actuar ha estado comprometido con la promoción del paramilitarismo por dar otro ejemplo-. Con todo esto, la significación del reconocimiento se ha ido perdiendo paulatinamente y con ello, la denominada alteridad, como presupuesto básico para la convivencia y por supuesto para la paz. Al tenor de Arendt: "La alteridad es un aspecto importante de la pluralidad, la razón por la que todas nuestras definiciones son distinciones, por la que somos incapaces de decir que algo es sin distinguirlo de alguna otra cosa". (2005) Lo que define al gobierno como status quo, distingue a la guerrilla como organización subversiva. Y, por otra parte, la paz podría definirse como lo opuesto a la guerra y viceversa. De todas formas, esto sería muy abstracto, pero muy cercano a lo que vive la sociedad colombiana.

\section{Conclusiones.}

Un proceso hacia la paz, necesita que los agentes revelen lo que son y lo que pueden hacer, para esto es indispensable el discurso y la acción con características de alteridad. Afortunadamente, el marco jurídico para la paz, como escenario jurídico posible -dentro de los estándares de justicia transicional, cuenta con la legitimación de la Corte Constitucional a través dela sentencia C-579 de 2013, pues estas son las reglas de juego para las eventuales acciones de las FARC y del gobierno. Así se obtiene una especie de alteridad jurídica suficiente, una delimitación de las acciones -para que sean menos imprevisibles e inciertas- y una mirada de la comunidad internacional como observadora y evaluadora del proceso. Es una mirada al pasado pensando en el futuro, donde las reglas pueden estimular la democracia o llevarla a un momento más crítico. Ya que,

Esa dinámica que La actividad política permitida y alentada por la institucionalización democrática tiene las reglas formales que ya conocemos y que prescriben tanto el funcionamiento de las propias instituciones como los límites, derechos y deberes de la acción individual o colectiva. Lo que llamamos las reglas de juego explícitas incluyen desde luego valores compartidos y asumidos históricamente, que, en consecuencia, componen el discurso político literalmente expuesto y consumido (...) Lo que nos permite discriminar entre extremos de ilegalidad, es lo que solemos denominar la buena fe, la honestidad de la práctica, de la corrección en el uso de las reglas de juego. (Raffin, M, 2006)

Menciona el profesor Raffin, es la que por momentos no se refleja en el procesualidad de la acción, pues la guerrilla, no deja de realizar acciones negativas condenables desde cualquier punto de vista, y el gobierno no es lo suficientemente claro respecto a la implementación institucional del acuerdo final, en caso de darse. De consuno, la ciudadanía se sorprende un poco y en algunos pasajes es incrédula frente a la promesa política de unos y otros. Esas acciones negativas deponen a las partes en el plano del mal, sin olvidar que una de las características de la acción, es precisamente la irreversibilidad de la misma -con toda justificación, debe evitarse este sentido negativo y causar el menor mal posible- y la impredecibilidad. Raffin afirma que:

Una acción que concierne al mal radical entra en el ámbito general de las acciones malas, "negativas" y puede engendrar, en consecuencia, dos tipos de reacciones: una nueva acción que la repite 
indefinidamente agregando una nueva negatividad a la que ya fue producida (la acumulación de las negatividades no podría resultar, en este caso en una positividad) o una nueva acción que termina con las consecuencias negativas, que establece un corte, a través de una refundación, un nuevo nacimiento, un acto nuevo que pone fin a las consecuencias negativas de la acción previa. La primera posibilidad constituye el caso de la venganza; la segunda puede dar lugar al perdón o al castigo. En este sentido, perdón y castigo, tal como lo expresa Arendt no se oponen y, en consecuencia, mantienen una relación intima e incluso recíproca (Raffin, M, 2006)

Lo anterior, es una clara muestra de lo que en Colombia se ha hecho como respuesta a las acciones (adversarias) del otro. La respuesta a la acción negativa ha sido históricamente la venganza. La continuidad de la negación es la constante dentro de la sociedad colombiana. Por eso, tiene valor cada intento por negociar el conflicto y aproximarse a algo desconocido para las partes, inclusive para el ciudadano, el perdón.

Colombia debe reconocer la importancia de construir un nuevo sentido del poder político, un sentido creativo, re-fundacional, vital y para ello, las acciones deben ser guiadas por principios de vida y dignidad humana como bien lo señala la Constitución de 1991. Para esto, las acciones que fueron inspiradas en la venganza durante cinco décadas, deben transformarse en acciones encaminadas hacia el perdón, y el castigo de aquellas conductas y violaciones a los derechos humanos y al derecho humanitario que responsabilicen a los contendores. La mirada de los conflictos no puede seguir siendo de amigo-enemigo, la mirada debe darse entre igualesdistintos, entre el pasado y el futuro, planteando un futuro, que vaya más allá de una promesa política y de un marco normativo de justicia transicional.

\section{Bibliografía.}

Sentencia C-370/06 (Corte Constitucional de Colombia 2006).

Aplicacipon del principio de oportunidad al desmovilizado de un grupo armado al margen de la ley, Sentencia C-936/10 (Corte Constitucional de Colombia 2010).

Archivos de graves violaciones a los DDHH., Infracciones al DIH, memoria histórica y conflicto armado.Elementos para una Política Pública. (2014). Bogota $\square$ : Centro Nacional de Memoria Histo $\square$ rica.

Arendt, H. (2005). La condición humana. Barcelona: Paidós.

Asamblea Nacional Constituyente. (2015 ). Constitución Política de 1991. Bogotá: Editorial Legis.

Centro Internacional para la Justicia Transicional. (2009). ¿Qué es la justicia transicional? Obtenido de www.ictj.org/es/: https://www.ictj.org/sites/default/files/ICTJ-GlobalTransitional-Justice-2009-Spanish.pdf

Centro Nacional de Memoria Histórica. (2013). ¡BASTA YA! Colombia: Memorias de guerra y dignidad. Bogotá: Centro Nacional de Memoria Histórica. 
Crocker, D. (2011). Comisiones de la verdad, justicia transicional y sociedad civil. En Justicia transicional. Bogotá: Siglo de Hombre Editores, Universidad de los Andes, Pontificia Universidad Javeriana.

Dussel, E. (2009). Política de la liberación: La arquitectónica. Madrid: Trotta.

García, R. (2006). Sistemas complejos. Barcelona: Gedisa.

Informe de la Sra. Diane Orentlicher, experta independiente encargada de actualizar el conjunto de principios para la lucha contra la impunidad, E/CN.4/2005/102 (CHR 18 de febrero de 2005).

Informe del Secretario General sobre el estado de derecho y la justicia de transición en las sociedades que sufren o han sufrido conflictos, S/2004/616 (Consejo de Seguridad de las Naciones Unidas 3 de agosto de 2004).

Instrumentos jurídicos de justicia transicional, Sentencia C-579/13 (Corte Constitucional de Colombia 2013).

Ley 418 de 1997 Por la cual se consagran unos instrumentos para la búsqueda de la convivencia, la eficacia de la justicia y se dictan otras disposiciones, Ley 418 de 1997 (Congreso de la república 26 de diciembre de 1997).

Ley de Justicia y Paz, Ley 975 de 2005 (Congreso de la República de Colombia 25 de julio de 2005).

Ley de víctimas y restitución de tierras, Ley 1448 de 2011 (Congreso de la república 10 de junio de 2011).

Mecanismos de justicia transicional previstos en ley 1424 de 2010, Sentencia C-771/11 (Corte Constitucional de Colombia 2011).

Orjuela Ruíz, A., \& Lozano Acosta, C. (2012). La indeterminación del campo de la justicia transicional en Colombia. Revista Estudios Socio-Jurídicos, 255-281.

Por la cual se dictan disposiciones de justicia transicional que garanticen verdad, justicia y reparación a las víctimas de desmovilizados de grupos organizados al margen de la ley, se conceden beneficios jurídicos y se dictan otras disposiciones, Ley 1424 de 2010 (Congreso de la república 29 de diciembre de 2010).

Por medio del cual se establecen instrumentos jurídicos de justicia transicional en el marco del artículo 22 de la Constitución Política y se dictan otras disposiciones, Acto legislativo 01 de 2012 (Congreso de la República de Colombia 31 de julio de 2012).

Raffin, M. (2006). La experiencia del horror. Subjetividad y derechos bumanos en las dictaduras y posdictaduras del cono sur. Buenos Aires: Editores del puerto. 
Semana. (9 de abril de 2012). Del 'bogotazo' al Día por las víctimas del conflicto. Obtenido de www.semana.com: http://www.semana.com/politica/articulo/del-bogotazo-diavictimas-del-conflicto/256123-3

Teitel, R. (2003). Genealogía de la justicia transicional. Harvard Human Rights Journal, 16, 69-94.

Uprimny Yepes, R., \& Guzmán Rodríguez, D. E. (2010). En búsqueda de un concepto transformador y participativo para las reparaciones en contextos transicionales. International Law: Revista Colombiana de Derecho Internacional, 231-286.

Weber, M. (1964). Economía y Sociedad. Esbozo de sociología comprensiva. Ciudad de México: Fondo de Cultura Económica.

\section{Nota.}

${ }^{i}$ El presente, es un escrito de investigación que hace parte de la sinergia académica por analizar y proponer escenarios, ideas, críticas y aportes desde el marco del proyecto de investigación institucional: Posconflicto, derecho y política, transformaciones institucionales de Colombia. Es también un esfuerzo relacionado con los estudios doctorales que adelanta el autor y una motivación ciudadana hacia una mejor Nación. 